\title{
Correction to: HARE: A new Hash-based Authenticated Reliable and Efficient Modified Merkle Tree Data Structure to Ensure Integrity of Data in the Healthcare Systems
}

\author{
Usharani Chelladurai $^{1}$. Seethalakshmi Pandian ${ }^{2}$
}

Received: 7 October 2020 / Accepted: 3 February 2021

๑) Springer-Verlag GmbH Germany, part of Springer Nature 2021

\section{Correction to: \\ Journal of Ambient Intelligence and Humanized Computing https://doi.org/10.1007/s12652-021-03085-0}

In the original publication of the article, the accepted date was incorrectly printed.

The correct date should read as

Accepted: 3 February 2021
The original article can be found online at https://doi.org/10.1007/ s12652-021-03085-0.

Usharani Chelladurai

usharani@aubit.edu.in

1 Departments of CSE, University College of Engineering, BIT Campus, Anna University, Tiruchirappalli, Tamil Nadu, India

2 Department of ECE, University College of Engineering, BIT Campus, Anna University, Tiruchirappalli, Tamil Nadu, India
The original article has been corrected.

Publisher's Note Springer Nature remains neutral with regard to jurisdictional claims in published maps and institutional affiliations. 